\title{
The impact of economic, social and cultural conditions on educational attainments ${ }^{\text {is }}$
}

\author{
Raffaele Lagravinese ${ }^{\mathrm{a}}$, Paolo Liberati ${ }^{\mathrm{b}}$, Giuliano Resce ${ }^{\mathrm{c}, *}$ \\ a Department of Economics and Finance, University of Bari “A. Moro” Largo Abbazia S. Scolastica, 70124 Bari, Italy \\ ${ }^{\mathrm{b}}$ Department of Economics and CEFIP, Roma Tre University, Via Silvio d'Amico, 77, 00145 Roma, Italy \\ ${ }^{\mathrm{c}}$ Institute of Clinical Physiology, National Research Council of Italy (IFC-CNR), Via G. Moruzzi, 1, 56124 Pisa, Italy
}

Received 19 October 2018; received in revised form 3 February 2019; accepted 10 March 2019

\begin{abstract}
This paper aims at investigating the effect of Economic Social and Cultural Status (ESCS) on the educational performances of students, using two waves of the Programme for International Student Assessment (PISA) survey of OECD $(2009,2012)$. The analysis is conducted at student level for all countries included in the PISA sample. The estimates are based on the Conditional Data Envelopment Analysis (DEA), applied for the first time in the Slack Based Measure (SBM) version. This method allows a detailed evaluation of the additional effort the students should do when they are operating in an ESCS that has a comparative disadvantage. The unprecedented use of a conditional non-radial model of efficiency, provides evidences of a significant effect of the ESCS on performances, with a strong heterogeneity among students, and countries. It follows that some problems with education may not be due to the education systems themselves, but to the economic, social and cultural gaps, which determine a persistence of inequality of opportunity. Thus, public policies are needed to foster virtuous paths to reduce disparities among students with different socioeconomic background both between and within systems.
\end{abstract}

(C) 2019 The Society for Policy Modeling. Published by Elsevier Inc. All rights reserved.

\section{JEL classifications: C14; I24; I28}

Keywords: Efficiency; Education; Inequality of opportunity

\footnotetext{
is The authors wish to thank Kristoff De Witte, Daniel Santin, Cinzia Daraio, and the participants to the IV workshop on "Efficiency in Education", Politecnico di Milano 20-21 October 2016, for useful comments. The authors are also in debt with Michele Raitano for the useful suggestions made to a preliminary version of the paper. A previous version of this paper was circulated as Ḧow Does Economic Social And Cultural Status Affect The Efficiency Of Educational Attainments? A Comparative Analysis On Pisa Results,D̈epartmental Working Papers of Economics - University 'Roma Tre' 0217, Department of Economics - University Roma Tre.

* Corresponding author.

E-mail address: gresce@ifc.cnr.it (G. Resce).
} 


\section{Introduction}

Over the last decade, the availability of detailed international surveys on cognitive achievement tests like the Programme for International Student Assessment (PISA) of OECD, has favoured many comparative analyses of the different educational systems. PISA in particular has led to the proliferation of international rankings and comparative analysis published in newspapers, technical reports and scientific studies (on pros and cons of PISA see Hopfenbeck).

Several works aimed at investigating the performances of educational systems have benefited from these data producing a voluminous literature on the subject. More specifically, some studies have attempted to analyse the efficient use of public expenditures looking at the educational outcome (see Afonso, Schuknecht, \& Tanzi, 2010; Agasisti, 2014; Annabi, 2017; Sibiano \& Agasisti, 2011; Sutherland, Price, \& Gonand, 2010). Other empirical works have investigated the effects of institutional variables and teaching strategies on the performance of pupils (Cordero \& Gil, 2018; Herbst \& Strawiński, 2016; Meroni, Vera-Toscano, \& Costa, 2015) and on the differences in PISA test between different types of school (Agasisti, 2011; Agasisti \& CorderoFerrera, 2013; Aparicio, Crespo-Cebada, Pedraja-Chaparro, \& Santín, 2017; Cherchye, De Witte, Ooghe, \& Nicaise, 2010; Crespo-Cebada, Pedraja-Chaparro, \& Santín, 2014; Ferraro \& Põder, 2018; Perelman \& Santin, 2011; Schütz, West, \& Wöbmann, 2007). Finally, a relevant amount of papers has been focussed on the importance of environmental factors on students' achievement (Agasisti \& Cordero, 2017; Bogetoft, Heinesen, \& Tranæs, 2015; Coco \& Lagravinese, 2014; De Witte \& Kortelainen, 2013; López-Torres \& Prior, 2015).

These latter studies, in line with the microanalysis based on different datasets (e.g. Chetty, Hendren, \& Katz, 2016), clearly show that rankings of educational systems may have limited value when the socio-economic background is not considered in the analysis, as the socio-economic status heavily influences employment prospects, health outcomes, concentration in the study, access to relevant networks (e.g. internet, newspapers, libraries) that matter to students' achievement.

In order to measure the family background at pupils' level, the PISA survey carried out a composite measure of background characteristics: the index of Economic, Social and Cultural Status (ESCS), which includes the employment status and the level of education of parents, as well as indicators of cultural and educational resources at home (as number of books, laptop, own room).

OECD employed this variable in order to estimate the equity of the educational systems in terms of the slope of the regression line that links the values of the ESCS index and the pupil performance. This is called "the socio-economic gradient" and suggests how much the score would increase when the ESCS index increases by one unit. The larger the increase, the more dependent the outcome to the ESCS index and, therefore, the less equitable the educational system.

Despite the extensive literature on efficiency in education, and the recognised effect of the socio-economic background on the education performances, it lacks a global perspective on equity and efficiency using the whole PISA sample and looking at ESCS as the main driver of score gap among different students.

To this regard, the aim of this work is to extend and improve the literature about equity and efficiency in education, along two lines. First, the paper investigates how the Economic Social and Cultural Status (ESCS) background affects the efficiency of educational attainments using micro-data of all countries analysed by the PISA survey. PISA test is particularly suitable for the purpose of this paper, since the survey is carried out on a representative sample of the population aged 15 years, in which the socio-economic background may still affects the outcome of the education process. This conditioning role of the ESCS, if any, should therefore be compensated when it represents inequality of opportunity (Roemer, 1998). 
Second, from a methodological perspective, the paper includes the consolidated procedure to embody environmental factors into Data Envelopment Analysis (DEA) - the conditional model of Ruggiero (1996) - in a non-radial version of DEA, which is the Slack Based Measure (SBM) model of Tone (2001). Using SBM, the paper assesses, for the first time, the effect of the ESCS on the overall Pareto-Koopmans efficiency at student level.

The analysis finds a significant effect of the Economic Social and Cultural Status on student performances, with a strong heterogeneity among students, and countries. Some of these trends, in particular the heterogeneity among variables, cannot be examined by using the traditional (radial) DEA. This is because the radial models can only estimate an index of overall efficiency, and they ignore what happens to the specific-variables considered. More in general, the different role of the ESCS in different aspects of education clearly reveals the importance to control for environmental factors when making decisions on the education systems.

The rest of the paper is organised as follows: Section 2 presents the data; Section 3 deals with problems related to the efficiency evaluation with environmental factors and it introduces the model; Section 4 shows the results of the efficiency performances and of the inequality analysis; Section 5 discusses some policy implications; Section 6 concludes.

\section{Data}

The analysis is conducted using micro data collected by the PISA surveys in 2009 and 2012. These surveys assess the knowledge and skills of 15-year old, mainly in industrialized countries, in three different subjects: mathematics, reading and scientific literacy. In selecting variables, the reference has been made to previous studies estimating the efficiency at student level on the PISA database (De Witte \& Kortelainen, 2013). This leads to using the total sum of learning time as an input (the sum of learning time in language, mathematics, and science), while three separate outputs are considered, given by the students' attainments on mathematics, language and sciences. The database contains 373,908 students in 2009, and 237,411 students in 2012, and covers 60 different countries. A summary descriptive statistic of the main variables is reported in Table 1.

Particularly important for the analysis is that the database provides a measure of the Economic, Social and Cultural Status (ESCS index), which can be used as a good approximation of inequality of opportunity among students, and - more in general - of all different backgrounds that may affect their educational performance. Indeed, the ESCS index is based on information on the students' status provided by themselves and calculated as the first Principal Component of three variables: a) the highest occupational status of parents; b) the highest educational level of parents;

Table 1

Descriptive statistics.

\begin{tabular}{|c|c|c|c|c|c|c|c|c|}
\hline \multirow[t]{2}{*}{ Variable } & \multicolumn{4}{|l|}{2009} & \multicolumn{4}{|l|}{2012} \\
\hline & Min & Aver. & Max. & S. dev. & Min. & Aver. & Max. & S. dev. \\
\hline ESCS & -6.62 & -0.23 & 3.53 & 1.13 & -5.66 & -0.18 & 3.69 & 1.09 \\
\hline Learn. time* $(x)$ & 120 & 661.65 & 2250 & 203.74 & 135 & 649.29 & 2420 & 210.44 \\
\hline Math score $\left(y_{1}\right)$ & 87.87 & 476.77 & 916.19 & 100.64 & 96.05 & 484.35 & 962.23 & 99.43 \\
\hline Lang. score $\left(y_{2}\right)$ & 70.20 & 477.21 & 871.12 & 96.23 & 86.59 & 487.05 & 904.80 & 96.17 \\
\hline Scien. score $\left(y_{3}\right)$ & 104.20 & 482.47 & 868.65 & 98.78 & 130.31 & 490.24 & 903.34 & 96.42 \\
\hline
\end{tabular}

Source: OECD PISA database.

Note: *minutes per week. 


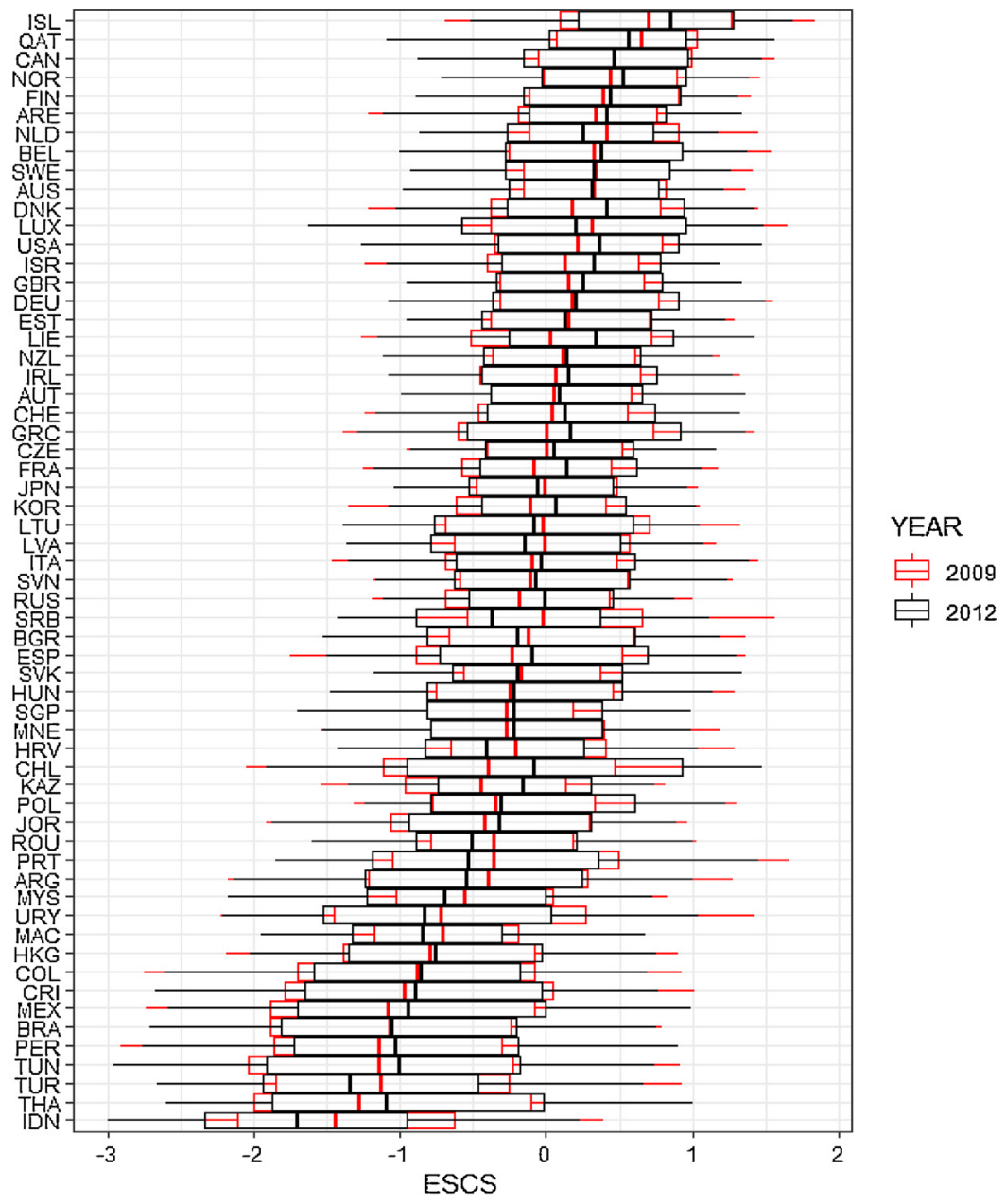

Fig. 1. ESCS indices 2009-2012.

c) the presence of home possessions. ${ }^{1}$ The final ESCS index is normalised to have mean zero and variance one in the OECD student population. ${ }^{2}$

As Fig. $1^{3}$ shows, the ESCS index has a widespread variability both between and within countries. In the 2009-2012, on average, higher levels of ESCS are in Northern Europe, Qatar, Canada, and Australia, while lower levels of ESCS are in South America, Mexico, Middle East and

\footnotetext{
${ }^{1}$ Home possession is a summary index of: A desk to study at; A room of your own; A quiet place to study; A computer you can use for school work; Educational software; A link to the Internet; Classical literature; Books of poetry; Works of art; Books to help with your school work; Technical reference books; A dictionary; A dishwasher; A player; Cellular phones; Televisions; Computers; Cars; Rooms with a bath or shower; Number of books at home.

2 The ESCS index of 2012 is centred at a different value, and it has some small differences in the considered variables, compared with the ESCS index of 2009. Even though there is both cross countries and over time consistency in the comparisons (OECD, 2014), the 2009 and 2012 results must be compared with caution.

3 The countries are sorted by the 2009-2012 median; the $5^{\text {th }}$ and $95^{\text {th }}$ percentiles are the extremes of the lines.
}

Please cite this article in press as: Lagravinese, R., et al. The impact of economic, social and cultural conditions on educational attainments. Journal of Policy Modeling (2019), https://doi.org/10.1016/j.jpolmod.2019.03.007 
South East Asian Countries. Interestingly, countries with high indices (above all the Scandinavian) show also less variability among students; on the contrary, countries with low indices (many Asians and South Americans) have also more variability among scholars.

\section{The empirical methodology}

In the DEA literature, the first model able to include environmental factors is presented by Banker and Morey (1986), which estimate an efficiency index based on the controllable input/output, but referring to a frontier operating in an equal or less favorable environment. The numerous techniques proposed after the Banker and Morey (1986) method, can be grouped in: 1) one-stage models, treating the environmental variables as special production factors (so that the estimated efficiency is conditional on the level of the environment); 2) two or more stages models, which ignore the environmental factors in the first stage, and adjust the results for the environmental effect in the following stages. ${ }^{4}$

Since the two or more stages procedure is valid only under a restrictive separability assumption (i.e., that the frontier of the attainable set does not change with changes of the environmental factors), we use a one-stage model for the analysis carried out in this paper. ${ }^{5}$ Efficiency evaluations are obtained by using the Slack Based Measure (SBM) model proposed by Tone (2001), which has three main advantages compared with other models:

a) it is non-oriented, in the sense that it does not require to choose between the output oriented or the input oriented approach;

b) it is non-radial, in the sense that it does not constrain the input and output vectors to improve proportionally (as the radial models do), but it estimates the maximum feasible improvement for each element in both vectors. ${ }^{6}$ This is relevant since we have a tri-dimensional output vector (test score in math, reading, and science);

c) it allows for a decomposition of the (aggregate) inefficiency indices into the variable-specific efficiency scores (input/outputs).

In order to detect the effect of the ESCS index on the overall efficiency at student level, an innovative methodology is proposed consisting in applying the conditional procedure suggested

\footnotetext{
${ }^{4}$ In the one-stage approach the environmental factor is treated either as inputs, as outputs, or as fixed factor, depending whether the effect on the production is respectively either positive, negative, or unknown. In the two-stage approach, the first stage includes only discretionary inputs/outputs, and in a second stage, the non-discretionary variables are regressed on the efficiency scores obtained in the first stage. Usually the adjustment is done by using either parametric tools (as Ray, 1991) or non-parametric tools (as Muñiz, 2002).

5 Separability may be a strong assumption for the purpose of this paper, as the ESCS used in the analysis is a clear relevant factor of production. Indeed, a relevant number of studies (among others Agasisti, 2011, 2013; Cordero-Ferrera, PedrajaChaparro, \& Salinas-Jiménez, 2008; Perelman \& Santin, 2011; Kirjavainen, 2012; Mancebón, Calero, Choi, \& Ximénezde-Embún, 2012; Thieme, Prior, \& Tortosa-Ausina, 2013; Crespo-Cebada et al., 2014; Podinovski, Ismail, BouzdineChameeva, \& Zhang, 2014; Aparicio et al., 2017) includes the socio-economic status (family, income, employment) in the inputs.

${ }^{6}$ With this characteristic, the SBM index of overall efficiency is able to embody all feasible improvements, namely the Pareto/Koopmans inefficiency that includes both the radial (the feasible proportional improvement or technical inefficiency as in Farrel, 1957) and the non-radial inefficiency (due to the non-optimal proportion of the elements in the input-output vectors or the mix inefficiency).
} 
in Ruggiero (1996) on the SBM model. ${ }^{7}$ The combination of these two models leads to detect the effect of ESCS on the overall efficiency index and at the same time to estimate its effect on the production of each output.

In more detail, for each student $k$ among the $611,319(n)$ pupils in the sample, one has:

- one input $x_{k}$ (total learning time, measured by minutes per week from OECD PISA database);

- three $(z)$ outputs (math score, language score, and science score from OECD PISA database) in the vector $\boldsymbol{y}_{\boldsymbol{k}}$ of dimension $(3 \times 1)$;

- one environmental variable $E S C S_{k}$ (the index of economic, social and cultural status from OECD PISA database).

Conditional and unconditional SBM indices of efficiency at student level are estimated. The unconditional estimates are made using the following standard SBM (Tone, 2001):

$$
\begin{gathered}
\min _{t_{U}, \lambda_{U j}, s_{U}^{-}, s_{U}^{+}} \tau_{U}=t_{U}-\frac{s_{U}^{-}}{x_{k}} \\
t_{U}+\frac{1}{z}\left(\sum_{r=1}^{z} \frac{s_{U r}^{+}}{y_{r k}}\right)=1 \\
t_{U} x_{k}=\sum_{j=1}^{n} x_{j} \lambda_{U j}+s_{U}^{-} \\
t_{U} \boldsymbol{y}_{\boldsymbol{k}}=\sum_{j=1}^{n} \boldsymbol{y}_{j} \lambda_{U j}-\boldsymbol{s}_{\boldsymbol{U}}^{+} \\
\sum_{j=1}^{n} \lambda_{U j}=t_{U} \\
t_{U}, \lambda_{U j}, s_{U}^{-}, s_{\boldsymbol{U}}^{+} \geq 0
\end{gathered}
$$

where $t_{U}$ is the variable of the linear transformation (Charnes \& Cooper, 1962); $s_{U}^{-}$is the unconditional input slack times $t_{U} ; s_{U}^{-} / t_{U}$ measures the learning time in excess at student level ignoring ESCS; $s_{U r}^{+}$is the unconditional $r^{\text {th }}$ output slack times $t_{U} ; s_{U r}^{+} / t_{U}$ measures the lack in the $r^{\text {rd }}$ attainment score at student level ignoring ESCS; and $\lambda_{U j}$ is a scalar variable of the intensity vector, times $t_{U}$.

By solving the linear program (1) we obtain $\tau_{U}$, which is the relative efficiency of the $k^{\text {th }}$ student unconditional on the level of ESCS, where $\left(1-\tau_{U}\right)$ is the estimated inefficiency. As the standard SBM models, this inefficiency is the relative average distance to the unconditional frontier, in each single variable considered in the analysis (learning time, test score math, test score reading, and test score science).

\footnotetext{
7 The model by Ruggiero (1996) has led to many applications in the educational sector (see, among others, Ouellette \& Vierstraete, 2010; Parteka \& Wolszczak-Derlacz, 2013; Essid, Ouellette, \& Vigeant, 2014).
} 
The conditional SBM to control for ESCS is instead obtained by the following linear program ${ }^{8}$

$$
\begin{gathered}
\min _{\mathrm{C}_{\mathrm{C}}, \lambda_{\mathrm{Cj}}, \mathrm{s}_{\mathrm{C}}^{-}, \mathrm{S}_{\mathrm{C}}^{+}} \tau_{C}=t_{C}-\frac{s_{C}^{-}}{x_{k}} \\
t_{C}+\frac{1}{z}\left(\sum_{r=1}^{z} \frac{s_{C r}^{+}}{y_{r k}}\right)=1 \\
t_{C} x_{k}=\sum_{j=1}^{n} x_{j} \lambda_{C j}+s_{C}^{-} \\
t_{C} \boldsymbol{y}_{k}=\sum_{j=1}^{n} \boldsymbol{y}_{j} \lambda_{C j}-\boldsymbol{S}_{C}^{+} \\
\sum_{j=1}^{n} \lambda_{C j}=t_{C} \\
t_{C}, \lambda_{C j}, s_{C}^{-}, S_{C}^{+} \geq 0 \\
\lambda_{C j}=0 \text { if ESC } S_{j}>E S C S_{k}
\end{gathered}
$$

where $t_{C}$ is the variable of the linear transformation (Charnes \& Cooper, 1962); $s_{C}^{-}$is the conditional input slack times $t_{C} ; s_{C}^{-} / t_{C}$ measures the learning time in excess at student level controlling for ESCS; $s_{C r}^{+}$is the conditional $r^{\text {th }}$ output slack times $t_{C} ; s_{C r}^{+} / t_{C}$ measures the lack in the $r^{\text {rd }}$ attainment score at student level controlling for ESCS; and $\lambda_{C j}$ is a scalar variable of the intensity vector, times $t_{C}$.

Solving the linear program (2) gives an estimate of $\tau_{C}$, which is the relative efficiency of the $k^{\text {th }}$ student conditional to its level of ESCS, where $\left(1-\tau_{C}\right)$ is the average distance to the conditional frontier, in each single variable considered in the analysis.

Model (2) is a SBM able to remove from the frontier those students operating in a better environment than the environment in which the $k^{\text {th }}$ student operates. Thus, the assumed technology is conditional on the level of ESCS. Indeed, following the algorithm suggested by Ruggiero (1996), Eq. (2) sets to zero the $\lambda_{C j}$ related to the students which have ESCS better than the ESCS of the evaluated student $(k)$. By this way, Model (2) allows to estimate the conditional overall Pareto-Koopmans efficiency. ${ }^{9}$

Following the definitions provided by Ruggiero (2000), Lozano-Vivas, Pastor, and Hasan (2001, 2002), Giménez, Prior, and Thieme, (2007); Bădin, Daraio, and Simar, (2012), and Johnson and Ruggiero (2014), the effect of ESCS on efficiency are estimated by using the frontier shifting between the unconditional and conditional evaluations to the level of ESCS. To this purpose, the SBM frontier shifting proposed in Tone (2004) is adapted as follows:

$$
\varphi=\frac{\tau_{C}}{\tau_{U}}=\frac{\text { Conditional Efficiency of the student }\left(x_{k}, \boldsymbol{y}_{\boldsymbol{k}}\right)}{\text { Unconditional Efficiency of the student }\left(x_{k}, \boldsymbol{y}_{\boldsymbol{k}}\right)}
$$

\footnotetext{
8 There is no open source or commercial software that implements Conditional SBM model. We have therefore developed an optization code in $\mathrm{R}$, that will be send on request of the interested scholars.

9 A previous non-radial conditional efficiency evaluation is in Baležentis and De Witte (2015), whose model is MultiDirectional based, since it is input oriented, and it does not estimate the overall Pareto-Koopmans efficiency because it ignores the residual output slacks.
} 
The coefficient $\varphi$ measures the shift of the frontier due to the environmental factor. Thus, it can be interpreted as an index of environmental harshness that indicates the possible negative impact that the ESCS has on the overall performances of the student. A value of $\varphi=1$ indicates the absence of any effect of ESCS on efficiency, since the frontier has not changed position controlling for it. A value of $\varphi>1$ indicates a comparative advantage in the performance for the students with better ESCS, since the frontier ignoring environmental factor is higher than the frontier controlling for it. In other words, $\varphi>1$ implies that some students that may result inefficient with respect to the unconditional frontier (i.e. without controlling for ESCS) are instead more efficient once the disadvantage of being in a less than optimal environment is controlled for. More generally, the higher is $(\varphi)$, the higher is the impact of ESCS on the performance of the student.

Since the analysis is micro-based, it allows to estimate both the effect of the ESCS on the level of efficiency, and the effect of the ESCS on the distribution of the performances. The first effect is computed aggregating student level indices both at the country and income group level, following the procedures proposed by Färe and Zelenyuk (2003, 2007), Färe and Grosskopf (2004), and Färe and Karagiannis (2014).

The effect of the ESCS on the distribution of efficiency is instead computed disentangling between and within countries inequality using the Theil index (Theil, 1967), which is a perfectly decomposable inequality index:

$$
T I=\sum_{i} f_{i}\left(\frac{\tau_{i}}{\mu}\right) \log \left(\frac{\tau_{i}}{\mu}\right)
$$

where $f i$ is the population share of student $i, \tau_{i}$ is the efficiency index of the student $i$.

The index (4) can be decomposed into a between and within group component as follows:

$$
T I=\left[\sum_{j} g_{j}\left(\frac{\mu_{j}}{\mu}\right) \log \left(\frac{\mu_{j}}{\mu}\right)\right]+\sum_{j} T I_{j} g_{j}\left(\frac{\mu_{j}}{\mu}\right)
$$

where $j$ refers to the sub-group, $g_{j}$ is the population share of group $j$ and $T I_{j}$ is the inequality in group $j$. The between component of inequality is captured by the first term, i.e., the level of inequality if everyone within each group $j$ had efficiency level $\mu_{j}$, the second term gives the within component of inequality (Elbers, Lanjouw, Mistiaen, \& Ozler, 2005; Cowell, 2000).

\section{Results}

The model proposed in this paper gives estimations of single efficiency indices at student level, covering 611,319 pupils in 60 different countries. This amount of information provides a relevant microeconomic basis of the macro analysis and allows detailed policy suggestions. For convenience Section 4.1 will first discuss the impact of ESCS at country level, while Section 4.2 will aggregate the outcomes by income group level. Finally, Section 4.3 will report some evidence on global inequalities.

\subsection{The effect of the ESCS at the country level}

The first step of the analysis is an efficiency evaluation that ignores the environmental factors (i.e., unconditional on ESCS). It is worth recalling that this starting point helps to isolate the 
effect of ESCS, as this effect is measured by the distance between the unconditional and the conditional frontier as in Eq. (3). The model used at this stage is the linear program (1), which is the unconditional SBM of Tone (2001). As reported in Section 2, the total learning time is used as input, while the outputs of the analysis are the students' attainments on the three subjects considered in PISA. The student performance is measured by the ability to achieve the maximum of attainments with the minimum of the learning time. In Table 2 we show the country level Minimum, Average, Maximum, and Standard deviation of the unconditional indices of the overall efficiency.

Table 2

Unconditional SBM scores (2009-2012).

\begin{tabular}{|c|c|c|c|c|c|c|c|c|c|c|}
\hline \multirow[t]{2}{*}{ Coun. } & \multicolumn{5}{|l|}{2009} & \multicolumn{5}{|l|}{2012} \\
\hline & Obs. & Min. & Aver. & Max. & S. dev. & Obs. & Min. & Aver. & Max. & S. dev. \\
\hline ARE & 7823 & 0.14 & 0.26 & 0.95 & 0.09 & 5598 & 0.14 & 0.27 & 0.95 & 0.11 \\
\hline ARG & 1409 & 0.14 & 0.25 & 0.93 & 0.14 & 1651 & 0.14 & 0.30 & 0.97 & 0.15 \\
\hline AUS & 11725 & 0.14 & 0.38 & 1.00 & 0.11 & 6915 & 0.14 & 0.37 & 0.89 & 0.10 \\
\hline AUT & 5373 & 0.14 & 0.48 & 0.99 & 0.16 & 2622 & 0.14 & 0.49 & 0.98 & 0.16 \\
\hline BEL & 6414 & 0.16 & 0.43 & 1.00 & 0.12 & 4081 & 0.15 & 0.42 & 0.96 & 0.11 \\
\hline BGR & 3933 & 0.15 & 0.41 & 0.90 & 0.12 & 3002 & 0.14 & 0.43 & 0.91 & 0.12 \\
\hline BRA & 18020 & 0.14 & 0.33 & 1.00 & 0.12 & 8111 & 0.14 & 0.36 & 1.00 & 0.14 \\
\hline CAN & 19092 & 0.14 & 0.28 & 1.00 & 0.12 & 12385 & 0.14 & 0.29 & 1.00 & 0.12 \\
\hline $\mathrm{CHE}$ & 10247 & 0.15 & 0.43 & 1.00 & 0.11 & 6484 & 0.14 & 0.43 & 1.00 & 0.12 \\
\hline $\mathrm{CHL}$ & 3761 & 0.14 & 0.28 & 0.96 & 0.10 & 2862 & 0.14 & 0.26 & 1.00 & 0.11 \\
\hline $\mathrm{COL}$ & 6486 & 0.14 & 0.32 & 0.97 & 0.13 & 4063 & 0.14 & 0.31 & 0.96 & 0.14 \\
\hline CRI & 3070 & 0.14 & 0.33 & 1.00 & 0.09 & 2528 & 0.17 & 0.35 & 0.90 & 0.10 \\
\hline $\mathrm{CZE}$ & 5297 & 0.16 & 0.41 & 0.96 & 0.13 & 3169 & 0.18 & 0.44 & 1.00 & 0.13 \\
\hline DEU & 3895 & 0.15 & 0.42 & 0.97 & 0.11 & 2313 & 0.14 & 0.42 & 0.94 & 0.11 \\
\hline DNK & 4684 & 0.14 & 0.35 & 0.96 & 0.10 & 4156 & 0.14 & 0.35 & 0.95 & 0.11 \\
\hline ESP & 20656 & 0.14 & 0.39 & 0.97 & 0.10 & 13923 & 0.15 & 0.42 & 0.97 & 0.11 \\
\hline EST & 4622 & 0.15 & 0.41 & 0.86 & 0.10 & 3062 & 0.17 & 0.43 & 0.89 & 0.10 \\
\hline FIN & 5601 & 0.15 & 0.52 & 1.00 & 0.12 & 5108 & 0.15 & 0.51 & 1.00 & 0.12 \\
\hline FRA & 3129 & 0.15 & 0.39 & 1.00 & 0.13 & 2108 & 0.16 & 0.41 & 0.97 & 0.13 \\
\hline GBR & 10195 & 0.14 & 0.35 & 0.92 & 0.09 & 7414 & 0.14 & 0.35 & 0.96 & 0.10 \\
\hline GRC & 4744 & 0.15 & 0.39 & 0.92 & 0.09 & 1068 & 0.24 & 0.41 & 0.61 & 0.06 \\
\hline HKG & 2669 & 0.15 & 0.32 & 0.92 & 0.09 & 2518 & 0.14 & 0.36 & 0.88 & 0.11 \\
\hline HRV & 4515 & 0.16 & 0.49 & 1.00 & 0.15 & 3099 & 0.15 & 0.47 & 1.00 & 0.15 \\
\hline HUN & 3922 & 0.14 & 0.49 & 0.99 & 0.13 & 2701 & 0.16 & 0.47 & 1.00 & 0.12 \\
\hline IDN & 3876 & 0.14 & 0.31 & 1.00 & 0.17 & 2690 & 0.14 & 0.34 & 1.00 & 0.17 \\
\hline IRL & 2938 & 0.16 & 0.48 & 1.00 & 0.12 & 2986 & 0.18 & 0.50 & 1.00 & 0.13 \\
\hline ISL & 3124 & 0.14 & 0.41 & 0.97 & 0.11 & 1909 & 0.15 & 0.40 & 0.88 & 0.11 \\
\hline ISR & 3850 & 0.14 & 0.37 & 0.97 & 0.13 & 2318 & 0.14 & 0.39 & 0.96 & 0.13 \\
\hline ITA & 25980 & 0.14 & 0.37 & 1.00 & 0.12 & 18139 & 0.14 & 0.39 & 0.97 & 0.11 \\
\hline JOR & 5988 & 0.14 & 0.26 & 0.90 & 0.06 & 3667 & 0.14 & 0.27 & 1.00 & 0.08 \\
\hline JPN & 5705 & 0.18 & 0.44 & 0.97 & 0.11 & 3872 & 0.17 & 0.45 & 1.00 & 0.13 \\
\hline KAZ & 5126 & 0.14 & 0.31 & 0.83 & 0.08 & 3042 & 0.14 & 0.42 & 0.99 & 0.17 \\
\hline KOR & 4974 & 0.18 & 0.44 & 0.94 & 0.09 & 3133 & 0.16 & 0.44 & 0.96 & 0.11 \\
\hline LIE & 308 & 0.17 & 0.43 & 1.00 & 0.12 & 187 & 0.15 & 0.48 & 0.92 & 0.12 \\
\hline LTU & 4082 & 0.14 & 0.41 & 0.96 & 0.11 & 2843 & 0.15 & 0.35 & 0.60 & 0.06 \\
\hline LUX & 4115 & 0.14 & 0.43 & 0.96 & 0.13 & 2926 & 0.16 & 0.44 & 0.97 & 0.12 \\
\hline LVA & 4357 & 0.15 & 0.37 & 0.95 & 0.09 & 2350 & 0.15 & 0.41 & 0.85 & 0.10 \\
\hline MAC & 5199 & 0.16 & 0.31 & 0.66 & 0.05 & 2808 & 0.16 & 0.36 & 0.80 & 0.09 \\
\hline MEX & 31919 & 0.14 & 0.31 & 1.00 & 0.10 & 18373 & 0.14 & 0.30 & 0.97 & 0.11 \\
\hline
\end{tabular}


Table 2 (Continued)

\begin{tabular}{|c|c|c|c|c|c|c|c|c|c|c|}
\hline \multirow[t]{2}{*}{ Coun. } & \multicolumn{5}{|l|}{2009} & \multicolumn{5}{|l|}{2012} \\
\hline & Obs. & Min. & Aver. & Max. & S. dev. & Obs. & Min. & Aver. & Max. & S. dev. \\
\hline MNE & 4077 & 0.17 & 0.45 & 0.93 & 0.11 & 2853 & 0.15 & 0.51 & 1.00 & 0.11 \\
\hline MYS & 2943 & 0.14 & 0.32 & 0.85 & 0.11 & 1894 & 0.14 & 0.35 & 0.98 & 0.15 \\
\hline NLD & 3054 & 0.17 & 0.49 & 1.00 & 0.13 & 2333 & 0.14 & 0.51 & 1.00 & 0.17 \\
\hline NOR & 4620 & 0.19 & 0.46 & 0.73 & 0.08 & 2663 & 0.14 & 0.45 & 1.00 & 0.12 \\
\hline NZL & 4239 & 0.14 & 0.36 & 0.88 & 0.09 & 2521 & 0.14 & 0.36 & 0.95 & 0.09 \\
\hline PER & 3106 & 0.14 & 0.26 & 0.95 & 0.12 & 1927 & 0.14 & 0.28 & 0.95 & 0.11 \\
\hline POL & 4852 & 0.17 & 0.40 & 0.74 & 0.07 & 2997 & 0.17 & 0.44 & 0.76 & 0.08 \\
\hline PRT & 3813 & 0.14 & 0.35 & 0.88 & 0.11 & 2341 & 0.14 & 0.32 & 0.95 & 0.11 \\
\hline QAT & 6198 & 0.14 & 0.26 & 1.00 & 0.10 & 3268 & 0.14 & 0.27 & 0.63 & 0.07 \\
\hline ROU & 3145 & 0.17 & 0.45 & 1.00 & 0.12 & 2759 & 0.16 & 0.43 & 0.94 & 0.14 \\
\hline RUS & 4684 & 0.14 & 0.33 & 0.96 & 0.10 & 3037 & 0.15 & 0.38 & 0.98 & 0.13 \\
\hline SGP & 4257 & 0.14 & 0.30 & 0.97 & 0.12 & 3670 & 0.15 & 0.34 & 1.00 & 0.07 \\
\hline SRB & 4449 & 0.15 & 0.42 & 0.98 & 0.15 & 2723 & 0.15 & 0.49 & 1.00 & 0.15 \\
\hline SVK & 4048 & 0.17 & 0.42 & 1.00 & 0.17 & 2286 & 0.16 & 0.46 & 1.00 & 0.18 \\
\hline SVN & 5498 & 0.14 & 0.46 & 0.97 & 0.10 & 2968 & 0.23 & 0.48 & 0.94 & 0.10 \\
\hline SWE & 4041 & 0.14 & 0.46 & 0.98 & 0.14 & 2788 & 0.16 & 0.44 & 0.95 & 0.12 \\
\hline THA & 5578 & 0.15 & 0.33 & 0.97 & 0.14 & 4031 & 0.15 & 0.35 & 1.00 & 0.14 \\
\hline TUN & 4873 & 0.15 & 0.27 & 0.59 & 0.04 & 1742 & 0.14 & 0.28 & 0.91 & 0.11 \\
\hline TUR & 4416 & 0.15 & 0.41 & 0.97 & 0.16 & 1671 & 0.20 & 0.43 & 0.99 & 0.15 \\
\hline URY & 4834 & 0.14 & 0.31 & 0.97 & 0.12 & 2130 & 0.16 & 0.43 & 1.00 & 0.17 \\
\hline USA & 4360 & 0.14 & 0.31 & 1.00 & 0.12 & 2625 & 0.14 & 0.31 & 1.00 & 0.13 \\
\hline
\end{tabular}

Note: The averages are weighted by the input shares.

Looking at Table 2, there is evidence of a widespread variability among the student performances within countries, as well as of some differences between the performances in 2009 and in 2012 (see also the correlation matrix in Table A1 in Appendix A). By considering the average performances of 2009 and 2012, many European countries are located in the upper side of the rank (the Scandinavian and the Northern-Eastern countries in particular), together with two Asian countries (North Korea and Japan). Instead, the bottom side of the rank includes many Middle Eastern countries (Qatar, Arab Emirates, and Jordan) and both North and South American countries (Chile, Peru, Argentina, Canada, Mexico, and USA). It is worth noting that some Eastern European countries (Kazakhstan, Serbia, Montenegro, Russia, Slovakia, and Poland), and SouthAmerican countries (Uruguay and Argentina) show a wide improvement in the period. On the contrary, a relevant reduction in the average performances of the students in the same period is observed in Lithuania and Portugal, together with smaller decreases of the average index in Chile, Sweden, Hungary and Croatia.

At this stage, however, nothing is said about the impact of the ESCS. To this purpose, it is needed to estimate the conditional efficiency by using the Conditional SBM described in Eq. (2). Given the measure of efficiency, the corresponding measure of inefficiency is calculated as the complement to the efficiency measure. In particular, the unconditional inefficiency is based on the distance between the evaluated student and the frontier ignoring the ESCS index, while the conditional inefficiency is based on the distance between the evaluated student and the frontier controlling for the ESCS. It is worth recalling that the frontier controlling for ESCS involves only those students who share an equal or less favourable environment compared with the environment in which the evaluated student operates. 
Table 3

Indices of economic, social and cultural harshness (2009-2012).

\begin{tabular}{|c|c|c|c|c|c|c|c|c|c|c|}
\hline \multirow[t]{2}{*}{ Coun. } & \multicolumn{5}{|l|}{2009} & \multicolumn{5}{|l|}{2012} \\
\hline & Obs. & Min. & Aver. & Max. & S. dev. & Obs. & Min. & Aver. & Max. & S. dev. \\
\hline ARE & 7823 & 1.00 & 1.00 & 1.40 & 0.01 & 5598 & 1.00 & 1.00 & 1.49 & 0.01 \\
\hline ARG & 1409 & 1.00 & 1.01 & 1.18 & 0.01 & 1651 & 1.00 & 1.01 & 1.35 & 0.01 \\
\hline AUS & 11725 & 1.00 & 1.01 & 1.56 & 0.01 & 6915 & 1.00 & 1.01 & 1.43 & 0.02 \\
\hline AUT & 5373 & 1.00 & 1.01 & 1.33 & 0.01 & 2622 & 1.00 & 1.01 & 1.17 & 0.01 \\
\hline BEL & 6414 & 1.00 & 1.01 & 1.54 & 0.02 & 4081 & 1.00 & 1.01 & 1.50 & 0.02 \\
\hline BGR & 3933 & 1.00 & 1.01 & 1.39 & 0.01 & 3002 & 1.00 & 1.01 & 1.73 & 0.03 \\
\hline BRA & 18020 & 1.00 & 1.02 & 2.83 & 0.04 & 8111 & 1.00 & 1.02 & 3.03 & 0.05 \\
\hline $\mathrm{CAN}$ & 19092 & 1.00 & 1.00 & 1.64 & 0.01 & 12385 & 1.00 & 1.01 & 1.48 & 0.01 \\
\hline $\mathrm{CHE}$ & 10247 & 1.00 & 1.01 & 1.79 & 0.02 & 6484 & 1.00 & 1.01 & 1.34 & 0.01 \\
\hline CHL & 3761 & 1.00 & 1.01 & 1.55 & 0.02 & 2862 & 1.00 & 1.01 & 1.46 & 0.01 \\
\hline $\mathrm{COL}$ & 6486 & 1.00 & 1.02 & 2.40 & 0.04 & 4063 & 1.00 & 1.02 & 1.80 & 0.04 \\
\hline CRI & 3070 & 1.00 & 1.02 & 1.75 & 0.04 & 2528 & 1.00 & 1.02 & 1.69 & 0.04 \\
\hline CZE & 5297 & 1.00 & 1.01 & 1.63 & 0.02 & 3169 & 1.00 & 1.01 & 1.19 & 0.01 \\
\hline DEU & 3895 & 1.00 & 1.01 & 1.36 & 0.02 & 2313 & 1.00 & 1.01 & 1.83 & 0.02 \\
\hline DNK & 4684 & 1.00 & 1.01 & 1.19 & 0.01 & 4156 & 1.00 & 1.00 & 1.14 & 0.01 \\
\hline ESP & 20656 & 1.00 & 1.01 & 1.49 & 0.02 & 13923 & 1.00 & 1.01 & 2.12 & 0.02 \\
\hline EST & 4622 & 1.00 & 1.01 & 1.27 & 0.01 & 3062 & 1.00 & 1.01 & 1.37 & 0.01 \\
\hline FIN & 5601 & 1.00 & 1.01 & 1.30 & 0.01 & 5108 & 1.00 & 1.01 & 1.64 & 0.02 \\
\hline FRA & 3129 & 1.00 & 1.01 & 1.38 & 0.02 & 2108 & 1.00 & 1.01 & 1.25 & 0.02 \\
\hline GBR & 10195 & 1.00 & 1.01 & 1.74 & 0.01 & 7414 & 1.00 & 1.01 & 1.87 & 0.02 \\
\hline GRC & 4744 & 1.00 & 1.01 & 1.35 & 0.01 & 1068 & 1.00 & 1.01 & 1.17 & 0.01 \\
\hline HKG & 2669 & 1.00 & 1.05 & 3.18 & 0.10 & 2518 & 1.00 & 1.04 & 2.48 & 0.07 \\
\hline HRV & 4515 & 1.00 & 1.01 & 1.17 & 0.01 & 3099 & 1.00 & 1.01 & 1.18 & 0.01 \\
\hline HUN & 3922 & 1.00 & 1.01 & 1.45 & 0.01 & 2701 & 1.00 & 1.01 & 1.68 & 0.02 \\
\hline IDN & 3876 & 1.00 & 1.02 & 2.26 & 0.04 & 2690 & 1.00 & 1.04 & 6.69 & 0.12 \\
\hline IRL & 2938 & 1.00 & 1.01 & 1.25 & 0.01 & 2986 & 1.00 & 1.01 & 1.20 & 0.01 \\
\hline ISL & 3124 & 1.00 & 1.00 & 1.11 & 0.01 & 1909 & 1.00 & 1.00 & 1.11 & 0.01 \\
\hline ISR & 3850 & 1.00 & 1.01 & 1.76 & 0.02 & 2318 & 1.00 & 1.01 & 2.06 & 0.03 \\
\hline ITA & 25980 & 1.00 & 1.01 & 1.75 & 0.02 & 18139 & 1.00 & 1.01 & 1.30 & 0.02 \\
\hline JOR & 5988 & 1.00 & 1.01 & 1.73 & 0.03 & 3667 & 1.00 & 1.01 & 2.56 & 0.05 \\
\hline JPN & 5705 & 1.00 & 1.01 & 1.56 & 0.02 & 3872 & 1.00 & 1.01 & 1.34 & 0.02 \\
\hline KAZ & 5126 & 1.00 & 1.01 & 5.90 & 0.07 & 3042 & 1.00 & 1.00 & 1.30 & 0.01 \\
\hline KOR & 4974 & 1.00 & 1.01 & 1.37 & 0.02 & 3133 & 1.00 & 1.01 & 1.43 & 0.02 \\
\hline LIE & 308 & 1.00 & 1.01 & 1.29 & 0.02 & 187 & 1.00 & 1.01 & 1.05 & 0.01 \\
\hline LTU & 4082 & 1.00 & 1.01 & 2.03 & 0.02 & 2843 & 1.00 & 1.01 & 1.58 & 0.02 \\
\hline LUX & 4115 & 1.00 & 1.01 & 1.30 & 0.01 & 2926 & 1.00 & 1.01 & 1.76 & 0.02 \\
\hline LVA & 4357 & 1.00 & 1.01 & 1.30 & 0.01 & 2350 & 1.00 & 1.01 & 1.16 & 0.01 \\
\hline MAC & 5199 & 1.00 & 1.02 & 3.11 & 0.05 & 2808 & 1.00 & 1.03 & 1.95 & 0.05 \\
\hline MEX & 31919 & 1.00 & 1.02 & 3.06 & 0.05 & 18373 & 1.00 & 1.02 & 2.46 & 0.04 \\
\hline MNE & 4077 & 1.00 & 1.01 & 1.10 & 0.01 & 2853 & 1.00 & 1.01 & 1.13 & 0.01 \\
\hline MYS & 2943 & 1.00 & 1.01 & 1.26 & 0.01 & 1894 & 1.00 & 1.01 & 1.18 & 0.01 \\
\hline NLD & 3054 & 1.00 & 1.01 & 1.42 & 0.02 & 2333 & 1.00 & 1.01 & 1.18 & 0.01 \\
\hline NOR & 4620 & 1.00 & 1.00 & 1.14 & 0.01 & 2663 & 1.00 & 1.00 & 1.55 & 0.01 \\
\hline NZL & 4239 & 1.00 & 1.01 & 2.25 & 0.03 & 2521 & 1.00 & 1.01 & 1.48 & 0.02 \\
\hline PER & 3106 & 1.00 & 1.02 & 1.70 & 0.04 & 1927 & 1.00 & 1.01 & 1.40 & 0.03 \\
\hline POL & 4852 & 1.00 & 1.01 & 1.20 & 0.01 & 2997 & 1.00 & 1.01 & 1.38 & 0.02 \\
\hline PRT & 3813 & 1.00 & 1.01 & 1.22 & 0.02 & 2341 & 1.00 & 1.01 & 1.32 & 0.02 \\
\hline QAT & 6198 & 1.00 & 1.00 & 1.17 & 0.01 & 3268 & 1.00 & 1.00 & 1.09 & 0.00 \\
\hline ROU & 3145 & 1.00 & 1.01 & 1.69 & 0.02 & 2759 & 1.00 & 1.01 & 3.59 & 0.08 \\
\hline
\end{tabular}


Table 3 (Continued)

\begin{tabular}{|c|c|c|c|c|c|c|c|c|c|c|}
\hline \multirow[t]{2}{*}{ Coun. } & \multicolumn{5}{|l|}{2009} & \multicolumn{5}{|l|}{2012} \\
\hline & Obs. & Min. & Aver. & Max. & S. dev. & Obs. & Min. & Aver. & Max. & S. dev. \\
\hline RUS & 4684 & 1.00 & 1.01 & 1.13 & 0.01 & 3037 & 1.00 & 1.01 & 1.20 & 0.01 \\
\hline SGP & 4257 & 1.00 & 1.03 & 1.53 & 0.04 & 3670 & 1.00 & 1.03 & 2.61 & 0.06 \\
\hline SRB & 4449 & 1.00 & 1.00 & 1.73 & 0.02 & 2723 & 1.00 & 1.01 & 1.16 & 0.01 \\
\hline SVK & 4048 & 1.00 & 1.01 & 1.39 & 0.01 & 2286 & 1.00 & 1.01 & 1.15 & 0.01 \\
\hline SVN & 5498 & 1.00 & 1.01 & 1.23 & 0.01 & 2968 & 1.00 & 1.01 & 1.21 & 0.01 \\
\hline SWE & 4041 & 1.00 & 1.00 & 1.13 & 0.01 & 2788 & 1.00 & 1.00 & 1.28 & 0.01 \\
\hline THA & 5578 & 1.00 & 1.02 & 1.70 & 0.03 & 4031 & 1.00 & 1.02 & 2.15 & 0.06 \\
\hline TUN & 4873 & 1.00 & 1.02 & 2.57 & 0.06 & 1742 & 1.00 & 1.02 & 3.70 & 0.10 \\
\hline TUR & 4416 & 1.00 & 1.02 & 1.76 & 0.04 & 1671 & 1.00 & 1.04 & 2.95 & 0.07 \\
\hline URY & 4834 & 1.00 & 1.01 & 1.80 & 0.02 & 2130 & 1.00 & 1.01 & 1.32 & 0.02 \\
\hline USA & 4360 & 1.00 & 1.01 & 1.47 & 0.01 & 2625 & 1.00 & 1.01 & 1.20 & 0.01 \\
\hline
\end{tabular}

Note: the averages are weighted on the input shares.

Results are reported in Table 3, where the numbers represent the country level minimum, average, maximum, and standard deviation of the ratios of the conditional to the unconditional efficiency. These ratios can be interpreted as an indicator of the Economic, Social and Cultural harshness at student level presented in Eq. (3).

The first relevant evidence is that the ESCS plays a role in shaping education performances. Indeed, as shown in Table 3, the indices of environmental harshness are relevant and pervasive, showing a strong variability within countries, between countries and across years. In particular, it can be observed that higher indices are expected in those countries where the ESCS are more heterogeneous, as this implies that the correction provided by the conditional estimates are more marked. Indeed, looking at the average of the period, the highest indices of ESCS harshness have been found in Hong Kong, Turkey, Macao, Indonesia, and Singapore. On the opposite side, one can find that Qatar, Island, Arab Emirates, Norway, Denmark, and Sweden have indices close to one, which means that there is no difference between student performances ignoring and controlling for ESCS.

In order to better describe the results obtained, a graphical representation of the unconditional efficiency and of the ESCS harshness at country level is reported in Fig. $2 .{ }^{10}$ Considering the average values of 2009 and 2012, four different groups of educational systems can be identified. In the upper right quadrant, there are countries showing the best performances in terms of unconditional efficiency, but also the biggest impact of the ESCS on efficiency (Turkey, Poland, Romania, Hungary, Croatia, Japan and Korea). In these cases, public authorities should develop supportive learning environments through concerted efforts of investing more in marginalized communities.

On the lower right quadrant in Fig. 2, instead, there are countries showing high performances and low ESCS harshness. Northern-European countries, including Scandinavian countries, fall into this class. As expected, the lower impact of the ESCS index is mainly explained by the relative greater homogeneity of social and cultural conditions in countries like Sweden, Denmark, Norway, Finland, Luxembourg, Iceland, and other similar countries (Esping-Andersen \& Wagner, 2012). These results are also partly explained by the numerous policies developed over the years (e.g., school autonomy, recruitment). In many Scandinavian countries, for example, greater autonomy of

10 2009-2012 averages weighted on the Input shares. The lines are on the median values. 


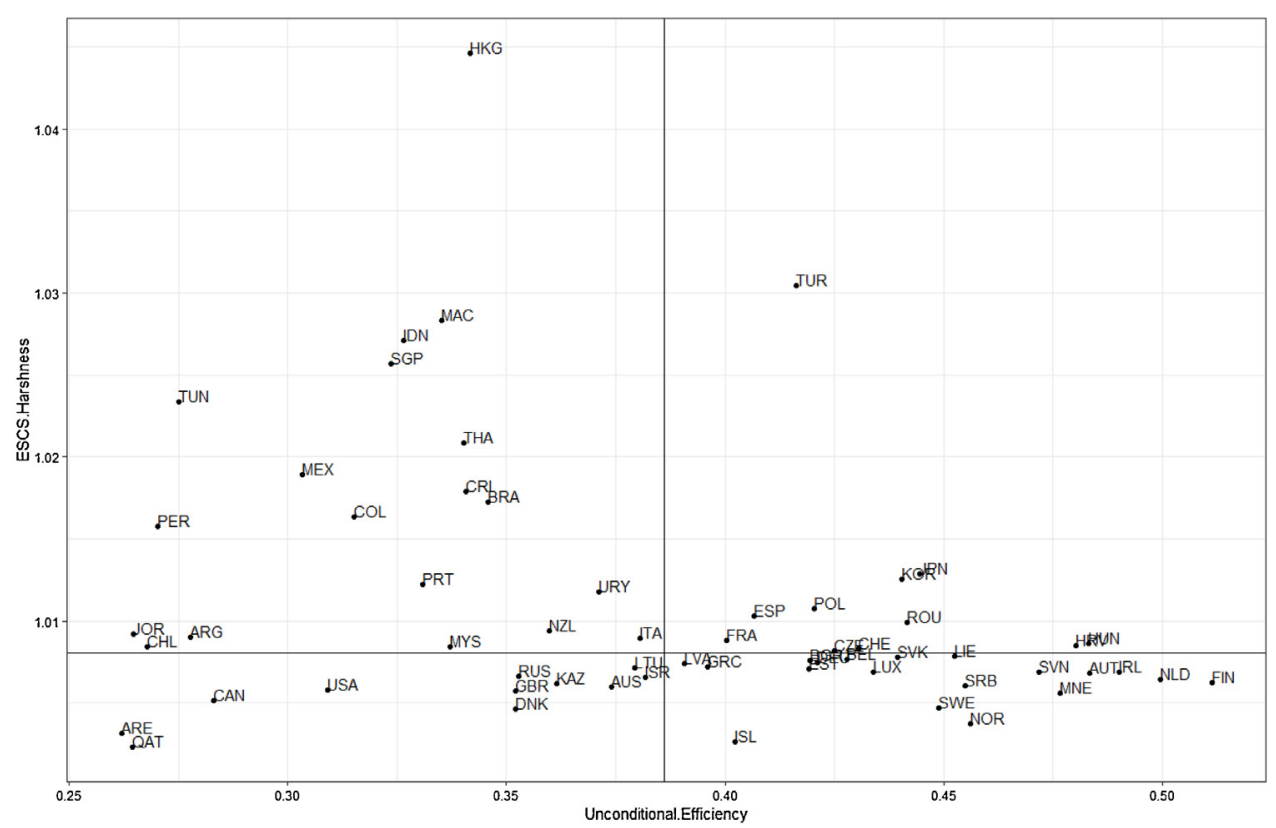

Fig. 2. Quadrant representation of unconditional efficiency and ESCS harshness at country level.

schools is encouraged, but developing a more supportive learning environment also comes through recruiting and training teachers and fostering effective learning strategies. Granting schools greater autonomy can be one option for improving learning outcomes. For instance, in Finland, teachers are entitled to a large degree of autonomy to adapt the pace of teaching to the pace of learning (OECD, 2018a).

On the lower left quadrant, there are countries with low unconditional efficiency and a low ESCS impact on the performances, including some Middle-East countries (Arab Emirates and Qatar) and the Anglo-Saxon systems (USA, Canada and UK). To some extent, this may imply that the measured inefficiency is independent from the ESCS, meaning that other sources of inefficiency (e.g., institutional factors, migration, etc.) may be important in explaining the underperformances at student level (Andersson, Östh, \& Malmberg, 2010, Chetty et al., 2016, Entorf \& Minoiu, 2005; Raitano \& Vona, 2016).

Finally, the upper left quadrant includes countries with low efficiency and a high ESCS harshness, which seems a characteristic of many South-East Asian countries (Hong Kong, Macao, Indonesia, Singapore, and Thailand), and of South American countries (Brazil, Colombia, and Argentina among others), again where the heterogeneity of the social and cultural conditions is strong, and where at least part of the measured inefficiency may indeed be due to the ESCS index. It is in these countries that, in order to get a general improvement of the education performances, it becomes particularly important to improve the student level of ESCS. In particular, policies to improve equity might include managing school choice to avoid segregation and increased inequities, making funding strategies responsive to students' and schools' needs and designing a variety of equivalent upper secondary education pathways, such as vocational training or apprenticeships (OECD, 2018a). 
Table 4

Average efficiencies for income group: high income (HI), upper medium income (UMI) and lower medium, income (LMI).

\begin{tabular}{|c|c|c|c|c|c|c|c|}
\hline \multirow[t]{2}{*}{ Index } & & \multicolumn{3}{|l|}{2009} & \multicolumn{3}{|l|}{2012} \\
\hline & & HI & UMI & LMI & HI & UMI & LMI \\
\hline \multirow{2}{*}{ Efficiency } & $\mathrm{U}$. & 0.37 & 0.32 & 0.31 & 0.38 & 0.34 & 0.34 \\
\hline & C. & 0.37 & 0.33 & 0.32 & 0.38 & 0.35 & 0.35 \\
\hline \multirow{2}{*}{ Learning T. slack } & $\mathrm{U}$. & 0.53 & 0.51 & 0.50 & 0.52 & 0.49 & 0.45 \\
\hline & C. & 0.58 & 0.61 & 0.62 & 0.57 & 0.59 & 0.59 \\
\hline \multirow{2}{*}{ Math slack } & $\mathrm{U}$. & 0.27 & 0.53 & 0.64 & 0.26 & 0.49 & 0.62 \\
\hline & C. & 0.12 & 0.20 & 0.22 & 0.12 & 0.19 & 0.20 \\
\hline \multirow{2}{*}{ Lang. slack } & $\mathrm{U}$ & 0.28 & 0.47 & 0.52 & 0.26 & 0.45 & 0.53 \\
\hline & C. & 0.14 & 0.16 & 0.13 & 0.12 & 0.16 & 0.12 \\
\hline \multirow{2}{*}{ Scien. slack } & $\mathrm{U}$ & 0.27 & 0.52 & 0.61 & 0.26 & 0.48 & 0.61 \\
\hline & C. & 0.13 & 0.20 & 0.20 & 0.12 & 0.19 & 0.19 \\
\hline
\end{tabular}

Notes: the average Efficiencies are weighted on the input shares; the slacks are the ratios of total slack on the total relative variable; $\mathrm{U}=$ unconditional, $\mathrm{C}=$ conditional.

\subsection{The effect of ESCS by income groups}

Of some interest, it is to investigate whether relevant differences that have been found among countries may have some definite patterns across the same countries when they are classified by income groups. To this purpose, the previous results are aggregated by income groups according to the World Bank's classification, and reported in Table 4, which includes the values of both unconditional (U) and conditional (C) efficiency for high income (HI), upper-medium income (UMI) and lower-medium income (LMI) countries. The first relevant evidence is that there is a general improvement in the performances between 2009 and 2012 for all income groups, a tendency that matches with the findings by OECD (2015). At the same time, the improvement is more marked in LMI and UMI countries, which may be at least partially an effect of a catching-up process of those countries that are lower in the efficiency scale, even though HI countries have best performances in both periods according to both $\mathrm{U}$ and $\mathrm{C}$ models. HI countries also show the lowest impact of the ESCS on the performances both in 2009 and in 2012, while efficiency - as expected - is higher in UMI and LMI countries when controlling for the ESCS.

Since the SBM model is non-radial, our overall efficiency index can be decomposed into the variable-specific efficiency scores, using the ratios of slacks on the original variables (see Section 3).

The slacks presented in Table 4 are the relative feasible improvements in each input/output. Two opposite trends in output and input slacks can be identified. On the output side, the unconditional slacks are higher than the corresponding conditional measures for all income groups both in 2009 and 2012. Furthermore, the difference between the unconditional and conditional slacks (the ESCS effect) increases when income decreases both in 2009 and 2012, suggesting that economic, social and cultural background may be more relevant in poorer countries. An opposite path is identified on the input side (learning time), where the unconditional slacks are lower than conditional slacks for all income groups both in 2009 and 2012. Also in this case, the difference between the unconditional and the conditional input slacks increases when income decreases. The reason for these evidences is that students living in $\mathrm{HI}$ countries have, on average, more learning 


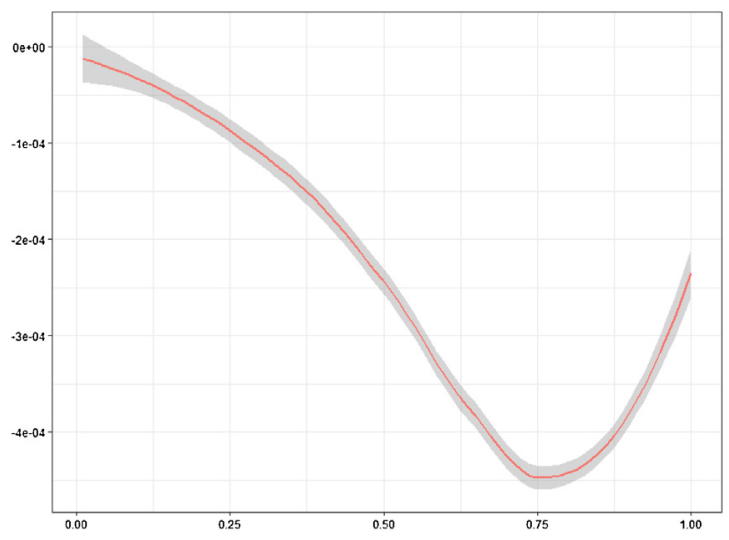

Fig. 3. Difference between Lorenz curve on conditional and unconditional indices of efficiency.

time than the students living in UMI and LMI countries ${ }^{11}$. It follows that when the LMI and UMI students are evaluated, the conditional input slacks are bigger than the unconditional input slacks (sixth, eigth, tenth, and twelfth row in Table 4), since the students on the conditional frontier (more UMI and LMI) are using less input than the students on the unconditional frontier (more $\mathrm{HI})$.

These relevant findings cannot be inspected by using the traditional radial measures of efficiency, because the radial models can only estimate an index of overall efficiency, and they ignore what happen to the specific-variables considered. Moreover, this evidence makes clear that ESCS are extremely relevant for policy decisions on the education systems. Neglecting the impact of this effect may not only lead to identify wrong results on the efficiency ranking of countries, but may also drive policymakers to wrong decisions and policy advices that may significantly differ from the outcomes obtained when controlling for ESCS.

From a policy perspecive, there is a significant part of inefficiency, expecially in UMI and LMI countries, that cannot be seen when the ESCS effect is not taken into account in the analysis. Furthermore, greater feasible improvements should be possible in UMI and LMI - especially in Maths and Science - if some of the disadvantageous ESCS conditions were removed. This makes a huge difference with the HI countries, where these feasible improvements are still possible but of less relevance.

\subsection{The inequalities in education performances}

In this section the country perspective is replaced by an analysis where efficiency at the student level is considered. In order to capture whether the ESCS has an impact on the inequality of the distribution of students' performances, Fig. $3^{12}$ reports the difference between the Lorenz curve of the unconditional efficiency indices (LU) and the Lorenz curve of the conditional efficiency indices (LC). It is of some relevance to note that LU always dominates LC, which means that

11 The average learning time 2009-2012 is: 665.26 in the HI countries, 632.20 in the UMI countries, and 596.37 in the LMI countries.

12 Grey is the $95 \%$ confidence interval. The shape does not change by using the concentration curves, and changing the cumulates (unconditional and conditional) by which the series are sorted. 
Table 5

Theil index.

\begin{tabular}{|c|c|c|c|c|c|c|c|c|}
\hline \multirow[t]{2}{*}{ Year } & \multicolumn{2}{|l|}{ Total } & \multicolumn{2}{|c|}{ Betw. macro reg. } & \multicolumn{2}{|c|}{ Betw. countries } & \multicolumn{2}{|c|}{ Within countries } \\
\hline & $\mathrm{U}$ & $\mathrm{C}$ & $\mathrm{U}$ & $\mathrm{C}$ & $\mathrm{U}$ & $\mathrm{C}$ & $\mathrm{U}$ & $\mathrm{C}$ \\
\hline 2009 & 0.0556 & 0.0559 & 0.0092 & 0.0089 & 0.0055 & 0.0055 & 0.0409 & 0.0415 \\
\hline 2012 & 0.0555 & 0.0560 & 0.0087 & 0.0085 & 0.0057 & 0.0057 & 0.0411 & 0.0418 \\
\hline
\end{tabular}

Notes: the macro regions are the subregional groups in the United Nations geoscheme; the between countries is estimated Within the macro regions; $\mathrm{U}=$ unconditional; $\mathrm{C}=$ conditional.

students' performances may appear more equally distributed when not controlling for ESCS. The explicit consideration of ESCS, instead, reveals that inequality is greater than that estimated by the conventional methods, by this way suggesting once more that controlling for ESCS is fundamental for the policy analysis.

This apparently counterintuitive result may be explained by the fact that when controlling for ESCS there are more students that becomes close to the maximum efficiency relative to their background, possibly generating a greater dispersion with respect to students that are left behind. In terms of the Lorenz curve, this means that LC may cumulate a greater number of high scores, by this way recording a higher concentration when students are ranked by their efficiency score level. Thus, what appears counterintuitive prima facie, is in line with the expected outcome of controlling for ESCS. When the unconditional frontier is shifted, more students are more efficient and obtain a higher score, which contributes to increase the distance among students that are inefficient because of a low ESCS and those that are instead inefficient for other reasons.

Total observed inequality can then be decomposed in order to estimate the variability between and within countries according to Eq. (5). To this purpose, Table 5 reports the Theil index for students' performances, with three additive components: the between macro regions (corresponding to the sub-regional groups in the United Nations geoscheme ${ }^{13}$ ); the between countries (estimated within the macro regions); and the within countries. The first relevant evidence is that almost the four-fifths of the global inequality in education performances is due to inequality within countries, which means that ESCS is a relevant variable to control for the heterogeneity of the initial conditions in any specific country. Indeed, the decreasing path of inequality between macro regions suggests that there is a convergence in the average performances of macro regions, both with the conditional and the unconditional approach. It is worth recalling that the average improvement of performances has involved LMI and UMI countries more than HI countries, a feature that has been interpreted as caused by some catching-up process of best performances. Combining this result with the inequality of performances may suggest that this catching-up may occur at the price of amplifying inequalities within macro regions and countries. Remarkably, the general tendency in the inequalities of education performances, seems in line with the trend of the world distribution of income (Arestis, Martin, \& Tyler, 2011; Liberati, 2015). This evidence extends to the findings reported in PISA (2012), about the link between inequality in literacy and numeracy skills, and inequality in the distribution of income.

Combining the information about the inequality of students' performances at country level with the corresponding information on inefficiency - as shown in Table A1 of Appendix A -

13 The considered sub-regional groups are: Australia and New Zealand; Central America; Central Asia; Eastern Asia; Eastern Europe; Northern Africa; Northern America; Northern Europe; South America; South-Eastern Asia; Southern Europe; Western Asia; and Western Europe. 
finally reveals that, on average, countries with more inequality are also the more inefficient. Thus, in line with Raitano and Vona (2016) and PISA (2012), the perceived trade-off between equity and efficiency in education (Hanushek, 2006) is not confirmed by our analysis.

\section{Policy implications}

Our analysis has revealed that efficiency in education is significantly affected by the economic, social and cultural status of the students in many countries. Indeed, with the possible exception of the richest North-European countries, the ESCS always plays a role in shaping the dispersion and the inequality of students' achievements. It follows that substantial improvements might be obtained if countries were able to remove the sometime extensive barriers to learning that the disadvantaged students face (OECD, 2018b).

In terms of detailed policy implications, it is not easy to find a common action that extremely different countries may implement, as different countries have usually different reasons why the economic, social and cultural conditions affect student performances. For example, OECD (2018b) suggests that the age at which the educational disadvantage starts may differ across countries; for some, the disadvantage starts at the early childhood, while for others it starts with the adolescence. Our analysis cannot control for this factor; however, it strongly supports the policy implication that a public intervention should start as early as possible, as disadvantages due to different background conditions tend to stratify over time, making more difficult to recover them at later stages. For this reason, it seems important that countries where the ESCS has a conditioning impact improve access to quality early childhood education by mitigating, if any, the enrolment fees through subsidies or cost reductions. Indeed, savings on these programs is only apparent, as they may lead to a considerable deterioration of the efficiency of students at a later stage, imposing costs to the society that may well overcome the budget savings obtained by not investing when it would be required.

It is worth noting that this observation does not hold only for low-income countries, where the background conditions of many students may be significantly deteriorated, but also for some richer countries, where it occurs that disadvantaged students are clustered in low-quality schools with a lower endowment of financial and human resources (OECD, 2018b;).

This causes disadvantaged students to attend disadvantaged schools. Indeed, according to our findings, some richer countries are not necessarily the best performers (as in the case of USA and countries in lower left quadrant in Fig. 2), while other richer countries (like the NorthernEuropean) rank higher in the efficiency scale, with the difference properly imputable to the different type of background conditions. It may happen that in richer countries that do not perform well, disadvantaged students are more concentrated in disadvantaged schools. Some evidence is found, for example, that in richer countries parents may want to pay more for housing in areas where the quality of school is higher, causing stratification among students that is not easily removable at later stages. Even though this outcome usually mirrors a general policy attitude, it is clear that funding these schools with more resources would be of great help for students' achievements.

On the other hand, those richer countries that perform better are usually countries where disadvantaged students are not concentrated in specific schools, because of more equality in the initial distribution of income and wealth. From a policy perspective, the different background conditions could be more easily removed by targeting individual students or their families with 
monetary support. Furthermore, educational outcomes may be affected by the way students spend their time outside of schools, as inequalities in extra-curricular attendance reinforce differences in non-cognitive skills. To this purpose, governments need to provide additional resources for freeof-charge tutoring in disadvantaged schools and programmes to develop social and emotional skills (OECD, 2018b).

This policy suggestion is in line with our finding that not only upper income countries, but also lower and medium income countries could achieve greater feasible improvements especially in Maths and Science if some of the disadvantageous ESCS conditions were removed (see the slacks presented in Table 4). More in general, our conclusions on the role of the ESCS give further support to those internationally suggested policies that are oriented to remove the possibility that the school choice is contingent to ability to pay or other discriminatory factors, as well as to policies that, in every country, may limit the opportunity for schools to skim off the best students (OECD, 2018b;). Public policies that combine after-school activities for underprivileged youth with a mentoring component can contribute to make sure disadvantaged youth stay enrolled and supplement skills not acquired at home.

\section{Conclusions}

This paper investigates the impact of Economic, Social, and Cultural Status on the education performances at student level, in all countries where the PISA data are available. The analysis is conducted at student level, allowing to combine micro and macro effects. In order to link the literature on efficiency and inequality, a methodology employed in efficiency studies has been used, with the aim of conditioning the results to the level of the ESCS index, widely investigated in the inequality of opportunity literature.

From a methodological perspective, the innovative feature of the paper is to combine the consolidated conditional procedure, proposed by Ruggiero (1996), with a non-radial model: the Slack Based Measure model proposed by Tone (2001). This methodology allows to detect a strong and widespread effect of the ESCS on students' performances. This effect has a pervasive heterogeneity among variables, students, and countries. Some of those heterogeneity, in particular the heterogeneity among the slacks in mathematics, language, and science, cannot be found by using the traditional (radial) DEA models. In many systems with pervasive inefficiencies (South American and South East Asian countries), a relevant part of the lacks is due to the presence of bad environments, as measured by a low ESCS. On the contrary, in many AngloSaxon and Middle East systems, the pervasive inefficiency is independent from the ESCS. These different roles of the ESCS in the presence of inefficiency in different countries clearly reveal the importance to control for environmental factors when making decisions on the educational systems. Furthermore, in line with some previous studies, there is evidence that some of the problems of education may not be due to the education systems themselves, but to the socioeconomic gaps.

\section{Appendix A.}


Table A1

A rank correlations (95\% bootstrap upper and lower bounds).

\begin{tabular}{|c|c|c|c|c|c|c|c|c|}
\hline & $\begin{array}{l}\text { Unc. } \\
2009\end{array}$ & $\begin{array}{l}\text { Unc. } \\
2012\end{array}$ & $\begin{array}{l}\text { Harsh. } \\
2009\end{array}$ & $\begin{array}{l}\text { Harsh. } \\
2012\end{array}$ & $\begin{array}{l}\text { Theil un. } \\
2009\end{array}$ & $\begin{array}{l}\text { Theil un. } \\
2012\end{array}$ & $\begin{array}{l}\text { Theil con. } \\
2009\end{array}$ & $\begin{array}{l}\text { Theil con. } \\
2012\end{array}$ \\
\hline Unc. 2009 & 1 & & & & & & & \\
\hline LB & 0.820 & & & & & & & \\
\hline Unc. 2012 & 0.904 & 1 & & & & & & \\
\hline UB & 0.951 & & & & & & & \\
\hline LB & -0.541 & -0.529 & & & & & & \\
\hline Harsh. 2009 & -0.298 & -0.262 & 1 & & & & & \\
\hline UB & -0.001 & 0.025 & & & & & & \\
\hline LB & -0.464 & -0.424 & 0.740 & & & & & \\
\hline Harsh. 2012 & -0.225 & -0.193 & 0.872 & 1 & & & & \\
\hline UB & 0.048 & 0.039 & 0.968 & & & & & \\
\hline LB & -0.627 & -0.599 & -0.217 & -0.112 & & & & \\
\hline Theil un. 2009 & -0.397 & -0.362 & 0.100 & 0.154 & 1 & & & \\
\hline UB & -0.117 & -0.111 & 0.391 & 0.404 & & & & \\
\hline LB & -0.663 & -0.615 & -0.147 & -0.198 & 0.472 & & & \\
\hline Theil un. 2012 & -0.462 & -0.402 & 0.117 & 0.091 & 0.675 & 1 & & \\
\hline UB & -0.208 & -0.151 & 0.349 & 0.350 & 0.834 & & & \\
\hline LB & -0.646 & -0.593 & -0.179 & -0.114 & 0.991 & 0.457 & & \\
\hline Theil con. 2009 & -0.407 & -0.372 & 0.123 & 0.179 & 0.998 & 0.672 & 1 & \\
\hline UB & -0.116 & -0.087 & 0.410 & 0.436 & 0.999 & 0.844 & & \\
\hline LB & -0.673 & -0.625 & -0.106 & -0.151 & 0.411 & 0.986 & 0.402 & \\
\hline Theil con. 2012 & -0.481 & -0.419 & 0.152 & 0.129 & 0.644 & 0.996 & 0.644 & 1 \\
\hline UB & -0.229 & -0.170 & 0.386 & 0.375 & 0.841 & 0.999 & 0.829 & \\
\hline
\end{tabular}

Note: the indices are at country level, bootstrap with 1000 replicates. Using R package by Herve (2015).

\section{References}

Afonso, A., Schuknecht, L., \& Tanzi, V. (2010). Income distribution determinants and public spending efficiency. The Journal of Economic Inequality, 8(3), 367-389.

Agasisti, T. (2011). How competition affects schools' performances: Does specification matter? Economics Letters, $110(3)$, 259-261.

Agasisti, T. (2013). The efficiency of Italian secondary schools and the potential role of competition: A data envelopment analysis using OECD-PISA 2006 data. Education Economics, 21(5), 520-544.

Agasisti, T. (2014). The efficiency of public spending on education: An empirical comparison of EU countries. European Journal of Education, 49(4), 543-557.

Agasisti, T., \& Cordero, J. M. (2017). The determinants of repetition rates in Europe: Early skills or subsequent parents' help? Journal of Policy Modeling, 39(1), 129-146.

Agasisti, T., \& Cordero-Ferrera, J. M. (2013). Educational disparities across regions: A multilevel analysis for Italy and Spain. Journal of Policy Modeling, 35(6), 1079-1102.

Andersson, E., Östh, J., \& Malmberg, B. (2010). Ethnic segregation and performance inequality in the Swedish school system: A regional perspective. Environment and planning A, 42(11), 2674-2686.

Annabi, N. (2017). Investments in education: What are the productivity gains? Journal of Policy Modeling, 39(3), 499-518.

Aparicio, J., Crespo-Cebada, E., Pedraja-Chaparro, F., \& Santín, D. (2017). Comparing school ownership performance using a pseudo-panel database: A Malmquist-type index approach. European Journal of Operational Research, 256(2), 533-542.

Arestis, P., Martin, R., \& Tyler, P. (2011). The persistence of inequality? Cambridge Journal of Regions, Economy and Society, 4(1), 3-11.

Bădin, L., Daraio, C., \& Simar, L. (2012). How to measure the impact of environmental factors in a nonparametric production model. European Journal of Operational Research, 223(3), 818-833.

Please cite this article in press as: Lagravinese, R., et al. The impact of economic, social and cultural conditions on educational attainments. Journal of Policy Modeling (2019), https://doi.org/10.1016/j.jpolmod.2019.03.007 
Baležentis, T., \& De Witte, K. (2015). One-and multi-directional conditional efficiency measurement-Efficiency in Lithuanian family farms. European Journal of Operational Research, 245(2), 612-622.

Banker, R. D., \& Morey, R. C. (1986). Efficiency analysis for exogenously fixed inputs and outputs. Operations Research, 34(4), 513-521.

Bogetoft, P., Heinesen, E., \& Tranæs, T. (2015). The efficiency of educational production: A comparison of the Nordic countries with other OECD countries. Economic Modelling, 50, 310-321.

Charnes, A., \& Cooper, W. W. (1962). Programming with linear fractional functionals. Naval Research Logistics Quarterly, 9(3-4), 181-186.

Cherchye, L., De Witte, K., Ooghe, E., \& Nicaise, I. (2010). Equity and efficiency in private and public education: A nonparametric comparison. European Journal of Operational Research, 202, 563-573.

Chetty, R., Hendren, N., \& Katz, L. F. (2016). The effects of exposure to better neighbourhoods on children: New evidence from the moving to opportunity experiment. The American Economic Review, 106(4), 855-902.

Coco, G., \& Lagravinese, R. (2014). Cronyism and education performance. Economic Modelling, 38, 443-450.

Cordero, J. M., \& Gil, M. (2018). The effect of teaching strategies on student achievement: An analysis using TALISPISA-link. Journal of Policy Modeling, 40(6), 1313-1331.

Cordero-Ferrera, J. M., Pedraja-Chaparro, F., \& Salinas-Jiménez, J. (2008). Measuring efficiency in education: An analysis of different approaches for incorporating non-discretionary inputs. Applied Economics, 40(10), 1323-1339.

Cowell, F. A. (2000). Measurement of inequality. In A. B. Atkinson, \& F. Bourguignon (Eds.), Handbook of income distribution (Vol. 1) (pp. 87-166). Elsevier.

Crespo-Cebada, E., Pedraja-Chaparro, F., \& Santín, D. (2014). Does school ownership matter? An unbiased efficiency comparison for regions of Spain. Journal of Productivity Analysis, 41(1), 153-172.

De Witte, K., \& Kortelainen, M. (2013). What explains the performance of students in a heterogeneous environment? Conditional efficiency estimation with continuous and discrete environmental variables. Applied Economics, 45(17), 2401-2412.

Elbers, C., Lanjouw, P., Mistiaen, J. A., \& Ozler, B. (2005). Re-interpreting sub-group inequality decompositions. World Bank, World Bank Policy Research Working Paper 3687., 42 p.

Entorf, H., \& Minoiu, N. (2005). What a difference immigration policy makes: A comparison of PISA scores in Europe and traditional countries of immigration. German Economic Review, 6(3), 355-376.

Esping-Andersen, G., \& Wagner, S. (2012). Asymmetries in the opportunity structure. Intergenerational mobility trends in Europe. Research in Social Stratification and Mobility, 30(4), 473.

Essid, H., Ouellette, P., \& Vigeant, S. (2014). Productivity, efficiency, and technical change of Tunisian schools: A bootstrapped Malmquist approach with quasi-fixed inputs. Omega, 42(1), 88-97.

Färe, R., \& Grosskopf, S. (2004). New directions: Efficiency and productivity. Dordrecht: Kluwer Academic Publishers.

Färe, R., \& Karagiannis, G. (2014). A postscript on aggregate Farrell efficiencies. European Journal of Operational Research, 233(3), 784-786.

Färe, R., \& Zelenyuk, V. (2003). On aggregate Farrell efficiencies. European Journal of Operational Research, 146(3), 615-620.

Färe, R., \& Zelenyuk, V. (2007). Extending Färe and Zelenyuk (2003). European Journal of Operational Research, 179(2), 594-595.

Ferraro, S., \& Põder, K. (2018). School-level policies and the efficiency and equity trade-off in education. Journal of Policy Modeling, 40(5), 1022-1037.

Giménez, V., Prior, D., \& Thieme, C. (2007). Technical efficiency, managerial efficiency and objective-setting in the educational system: An international comparison. Journal of the Operational Research Society, 58(8), 996-1007.

Hanushek, E. A. (2006). Does educational tracking affect performance and inequality? Differences-in-differences evidence across countries. The Economic Journal, 116(510), C63-C76.

Herbst, M., \& Strawiński, P. (2016). Early effects of an early start: Evidence from lowering the school starting age in Poland. Journal of Policy Modeling, 38(2), 256-271.

Herve, M. (2015). RVAideMemoire: Diverse basic statistical and graphical functions. $R$ package version0.9-52. http://CRAN.R-project.org/package=RVAideMemoire

Johnson, A. L., \& Ruggiero, J. (2014). Nonparametric measurement of productivity and efficiency in education. Annals of Operations Research, 221(1), 197-210.

Kirjavainen, T. (2012). Efficiency of Finnish general upper secondary schools: An application of stochastic frontier analysis with panel data. Education Economics, 20(4), 343-364.

Liberati, P. (2015). The world distribution of income and its inequality, 1970-2009. Review of Income and Wealth, 61(2), $248-273$

Please cite this article in press as: Lagravinese, R., et al. The impact of economic, social and cultural conditions on educational attainments. Journal of Policy Modeling (2019), https://doi.org/10.1016/j.jpolmod.2019.03.007 
López-Torres, L., \& Prior, D. (2015). Should we charge environmental factors for poor students' achievement? Applied Economics Letters, 22(17), 1378-1381, 41-54.

Lozano-Vivas, A., Pastor, J. T., \& Hasan, I. (2001). European bank performance beyond country borders: What really matters? European Finance Review, 5(1-2), 141-165.

Lozano-Vivas, A., Pastor, J. T., \& Pastor, J. M. (2002). An efficiency comparison of European banking systems operating under different environmental conditions. Journal of Productivity Analysis, 18(1), 59-77.

Mancebón, M. J., Calero, J., Choi, Á., \& Ximénez-de-Embún, D. P. (2012). The efficiency of public and publicly subsidized high schools in Spain: Evidence from PISA - 2006. Journal of the Operational Research Society, 63(11), 1516-1533.

Meroni, E. C., Vera-Toscano, E., \& Costa, P. (2015). Can low skill teachers make good students? Empirical evidence from PIAAC and PISA. Journal of Policy Modeling, 37(2), 308-323.

Muñiz, M. A. (2002). Separating managerial inefficiency and external conditions in data envelopment analysis. European Journal of Operational Research, 143(3), 625-643.

OECD. (2014). Scaling Procedures and Construct Validation of Context Questionnaire Data. PISA 2012 technical report, Paris.

OECD. (2015). How has student performance evolved over time? Paris: PISA in focus, no. 47, OECD Publishing.

OECD. (2018a). A broken social elevator? How to promote social mobility. Paris: OECD Publishing. http://dx.doi.org/10.1787/9789264301085-en

OECD. (2018b). Equity in education: Breaking down barriers to social mobility. Paris: PISA, OECD Publishing. http://dx.doi.org/10.1787/9789264073234-en

Ouellette, P., \& Vierstraete, V. (2010). Malmquist indexes with quasi-fixed inputs: An application to school districts in Québec. Annals of Operations Research, 173(1), 57-76.

Parteka, A., \& Wolszczak-Derlacz, J. (2013). Dynamics of productivity in higher education: Cross-European evidence based on bootstrapped Malmquist indices. Journal of Productivity Analysis, 40(1), 67-82.

Perelman, S., \& Santin, D. (2011). Measuring educational efficiency at student level with parametric stochastic distance functions: An application to Spanish PISA results. Education Economics, 19(1), 29-49.

PISA, O. (2012). Results: Excellence through Equity-Giving Every Student the Chance to Suc-ceed. 2014-10-12] file://D:/JSong_EDU/Desktop/pisa-2012-resuhs, 2.

Podinovski, V. V., Ismail, I., Bouzdine-Chameeva, T., \& Zhang, W. (2014). Combining the assumptions of variable and constant returns to scale in the efficiency evaluation of secondary schools. European Journal of Operational Research, 239(2), 504-513.

Raitano, M., \& Vona, F. (2016). Assessing students' equality of opportunity in OECD countries: The role of national-and school-level policies. Applied Economics, 48(33), 3148-3163.

Ray, S. C. (1991). Resource-use efficiency in public schools: A study of Connecticut data. ManagementScience, 37(12), $1620-1628$.

Roemer, J. E. (1998). Equality of opportunity. Cambridge, MA: Harvard University Press.

Ruggiero, J. (2000). Nonparametric estimation of returns to scale in the public sector with an application to the provision of educational services. Journal of the Operational Research Society, 51(8), 906-912.

Ruggiero, J. (1996). On the measurement of technical efficiency in the public sector. European Journal of Operational Research, 90, 625-643.

Schütz, G., West, M. R., \& Wöbmann, L. (2007). School accountability, autonomy, choice, and the equity of student achievement: International evidence from PISA 2003. OECD education working paper, No. 14, OECD.

Sibiano, P., \& Agasisti, T. (2011). Efficiency of public spending in education: A challenge among Italian regions. Investigaciones de Economía de la Educación, 6, 503-516.

Sutherland, D., Price, R., \& Gonand, F. (2010). Improving public spending efficiency in primary and secondary education. OECD Journal: EconomicStudies, 2009(1), 1-30.

Theil, H. (1967). Economics and information theory North-Holland, Amsterdam.

Thieme, C., Prior, D., \& Tortosa-Ausina, E. (2013). A multilevel decomposition of school performance using robust nonparametric frontier techniques. Economics of Education Review, 32(1), 104-121.

Tone, K. (2004). Malmquist productivity index. In Handbook on data envelopment analysis. pp. 203-227. US: Springer.

Tone, K. (2001). A slacks-based measure of efficiency in data envelopment analysis. European Journal of Operational Research, 130, 498-509. 